\title{
Geotextile Tubes Application on Beach Nourishment in UAE
}

\author{
Andy Chien, Shelly Wu, Felix Tseng, and Amy Tang
}

\begin{abstract}
The most common application of geotextile tubes can be found in marine engineering. It could be applied as various structures, such as jetty, submerged breakwater, or revetment with beneficial features of easy installation, eco-friendliness and cost-effectiveness. The application of this method is boomed in recent years. And this project is located at Al Aqah Beach Fujairah, UAE. Existing rubble groins were lacked of substantial protection and weakened gradually. Serious erosion problem was found after Hurricane Gonu. This disaster affected the local tourism industry significantly. Taking tourist attractions, project budget, and environmental demands into consideration, the client chose geotextile tubes to rebuild the groin and submerged breakwater to achieve the purpose of beach nourishment.
\end{abstract}

Index Terms-Geotextile tube, groin, submerged breakwater, beach nourishment.

\section{INTRODUCTION}

Shoreline change is a gradual and natural phenomenon; the longshore current help in managing sediment transport and keeping the shoreline stable. However, the construction of man-made structure may break the overall stability [1] of such phenomenon, making the change of shoreline unstable; in addition, the occurrence of drifting sand caused by hurricane has a tremendous impact to the environment. In 2007, Hurricane Gonu hit Fujairah and caused significant erosion to the coastal beach for some kilometers. Among which, the Al Aqah beach was found the most serious one. Although the local longshore current was able to perform sediment transport from the south to the north and carry to erosion areas, the natural sedimentation will take years to restore to the original coastal landform. And possible natural disasters may cause damage to those areas again while they are still recovering.

In this particular project, there were two rubble groins, one at the north side and the other at the south side, to protect the beach in front of a hotel. No protection was done to the foundation of the rubble groins. After a period of time, wave action and impact of hurricane caused significant subsidence and damage to the groins; their effective height and length were reduced that their sand intercepting function was decreased as shown in Fig. 1. Considering tourism, environmental protection, and budget, the hotel owner wanted to enhance the groin structure and restore the beach without disturbing the landscape.

Manuscript received December 20, 2013; revised March 6, 2014.

The authors are with ACE Geosynthetics, Taiwan, R.O.C. (e-mail: andy.chien@geoace.com, shelly.wu@geoace.com, felix.tesng@geoace.com, amy.tang@geoace.com).

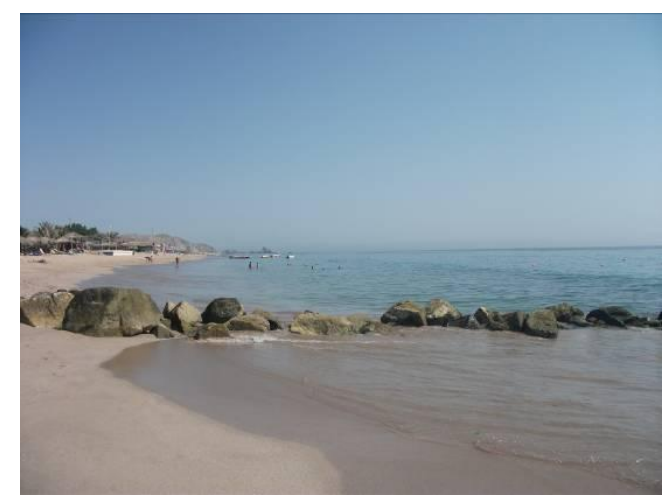

Fig. 1. This figure shows the situation of rubble groin after subsidence.

\section{DESIGN CONCEPT}

This project was designed to construct a 200 meters long groin at both the north and the south side of the protective beach. Then a submerged breakwater of $225 \mathrm{~m}$ in length will be built perpendicularly at the end of groins to form a $\Pi$ -shape structure [2], [3]. And lastly, backfilling the sea sand into the closing area for beach nourishment. Making use of the submerged breakwater to weaken, shoal, and break waves, beach erosion caused by natural forces could be reduced. Considering the high cost of rock in the local market, possible environmental impact, overall project cost, project duration, and the local tourist attractions, the client decided to use geotextile tubes to construct the groins and submerged breakwater.

Construction with geotextile tube was simple, only a sand pump or small dredger would be needed to pump the in-situ sea sand into the geotextile tubes. This method caused minimal environment impact and would not affect the landscape. In order to match the topography, two types of geotextile tube [3] were used: Type IV (see Fig. 2) and Type III (see Fig. 3). Type IV geotextile tube had a circumference of $8.6 \mathrm{~m}, 52 \mathrm{~m}$ in length, and an unilateral scour apron and anchor tube. Type III geotextile tube had a circumference of $17.2 \mathrm{~m}, 52 \mathrm{~m}$ in length and with bilateral scour apron and anchor tube.

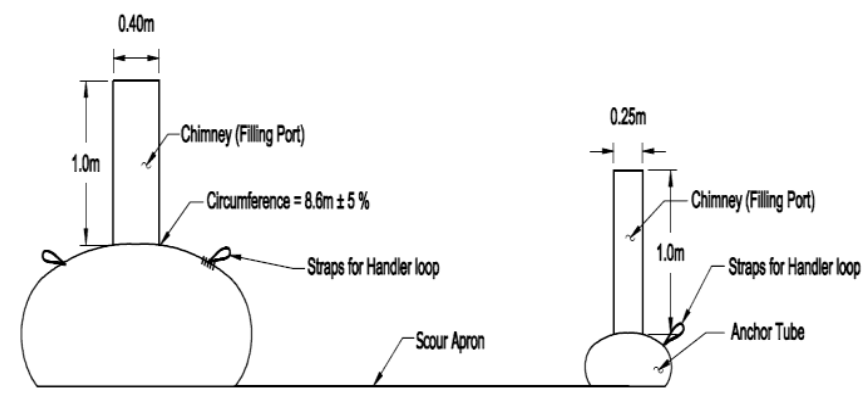

Fig. 2. Type IV geotextile tube drawing. 


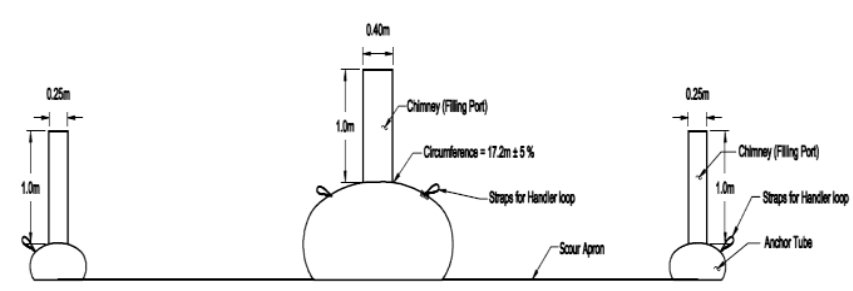

Fig. 3. Type III geotextile tube drawing.

Geosynthetic Confined Pressurized Slurry (GeoCoPS) [4], the professional analysis software, was used to analyze and determine the designed height of the geotextile tubes (with $8.6 \mathrm{~m}$ and $17.2 \mathrm{~m}$ in circumference) under designed conditions. Assuming the unit of slurry pumped into the geotextile tubes was $15 \mathrm{kN} / \mathrm{m} 3$, after natural settlement and compaction the slurry unit became $18 \mathrm{kN} / \mathrm{m} 3$. The reduction factors recommended by GeoCoPS Supplemental Notes were adopted: the installation damage reduction factor was 1.3 , the seam strength reduction factor was 2.0, the chemical and degradation reduction factor was 1.0 , and the creep reduction factor was 1.5 [5]. The analysis result showed that the height of geotextile tube with $8.6 \mathrm{~m}$ circumference after filling was $1.5 \mathrm{~m}$ as shown in Fig. 4. The height of the $17.2 \mathrm{~m}$ circumference one was $3 \mathrm{~m}$ as shown in Fig. 5.

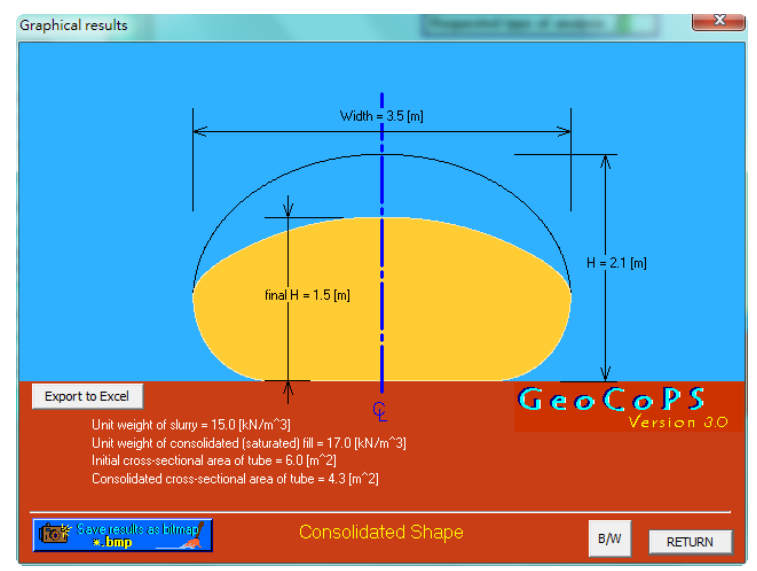

Fig. 4. Analysis result of $8.6 \mathrm{~m}$ circumference by GeoCoPS.

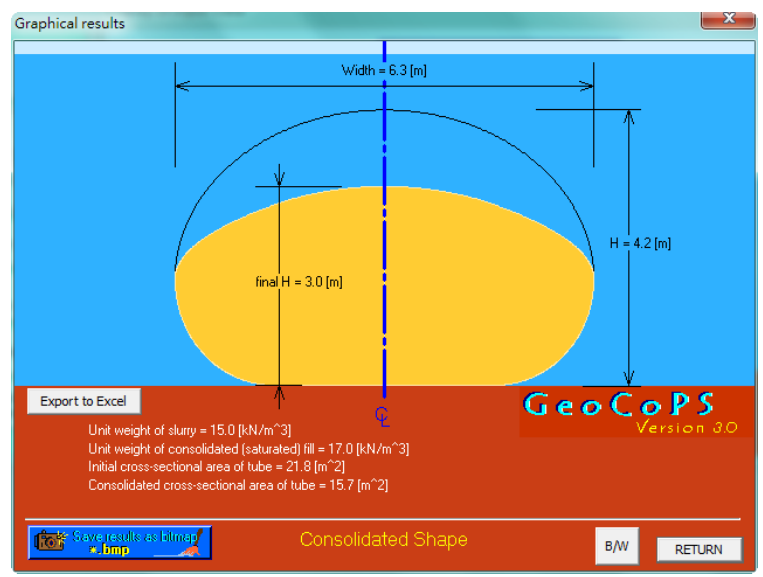

Fig. 5. Analysis result of $17.2 \mathrm{~m}$ circumference by GeoCoPS.

The construction of groin was divided into two parts. The near shore part of the groin was designed to place four Type IV geotextile tubes in two rows, to form the first half of the groin with $100 \mathrm{~m}$ in length and $7 \mathrm{~m}$ in width. There were scour apron and anchor tube at both sides of the groins. The sea side part of groin was designed to use two Type III geotextile tubes, to complete the latter part of $100 \mathrm{~m}$ in length and $7.5 \mathrm{~m}$ in width. Both sides of the tubes also carried the scour apron and anchor tube to prevent the foundation erosion (see Fig. 7).

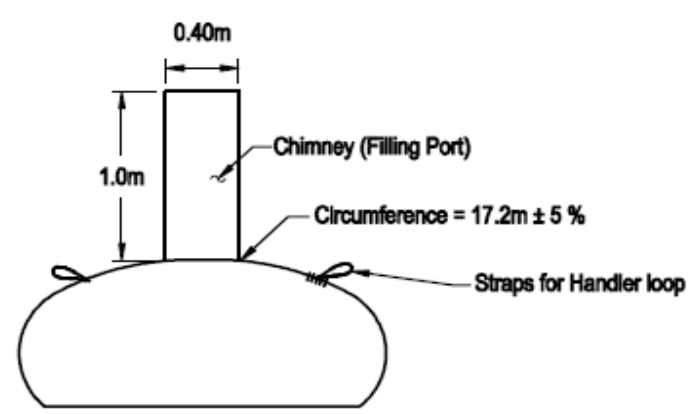

Fig. 6. Type I geotextile tube drawing.

The submerged breakwater was designed to use two types of geotextile tubes: Type I (see Fig. 6) and Type II (see Fig. 8 ). Type I had a circumference of $17.2 \mathrm{~m}$ and $77 \mathrm{~m}$ in length without scour apron and anchor tube. Type II also had a circumference of $17.2 \mathrm{~m}$ and $77 \mathrm{~m}$ length but it carried unilateral scour apron and anchor tube. These two specifications had the same circumference as Type III, so the designed height was also in $3 \mathrm{~m}$ as Type III. The submerged breakwater and the two groins formed a $\Pi$-shape structure of $225 \mathrm{~m}$ by $228 \mathrm{~m}$, and the enclosure was to be backfilled with sea sand for beach nourishment.

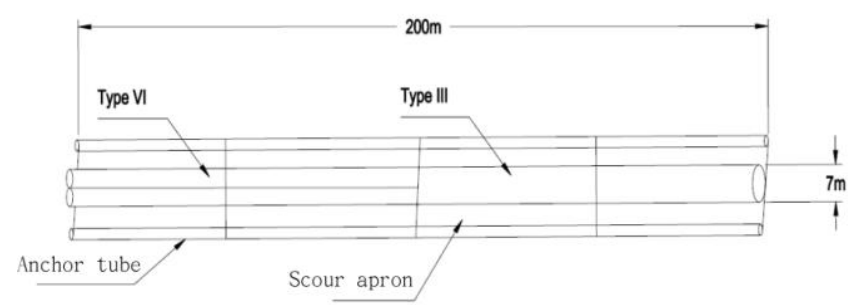

Fig. 7. The top view of groin design drawing.

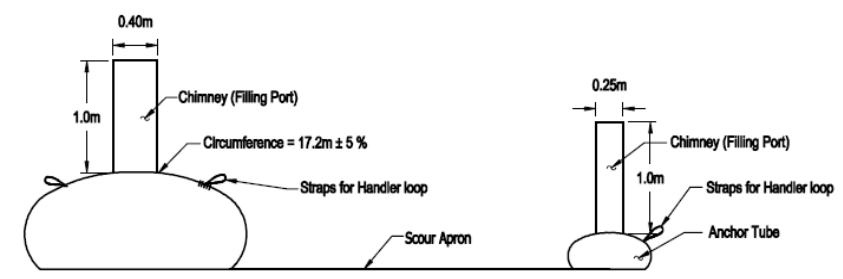

Fig. 8. Type II geotextile tube drawing.

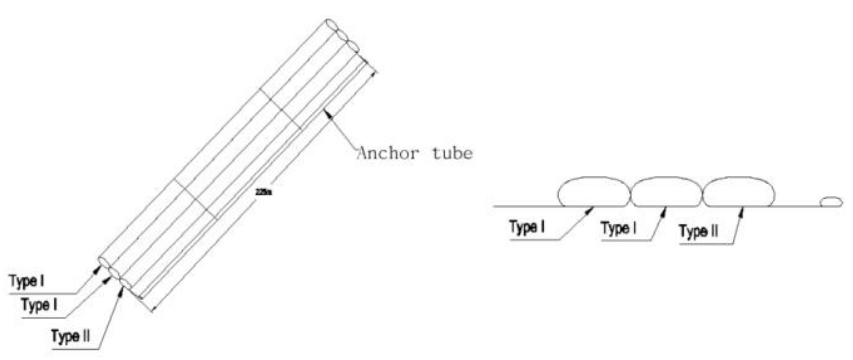

Fig. 9. The top view and lateral view of submerged breakwater drawing.

The submerged breakwater would be placed $200 \mathrm{~m}$ away from and parallel to the beach. The designed wave height at the front of the submerged breakwater was $3 \mathrm{~m}$, and the water depth was $6 \mathrm{~m}$. Analysis showed that the stability of this submerged breakwater design was very safe [2], [6], [7]. 
When the wave transported over the submerged breaker, the wave would shoal and break.

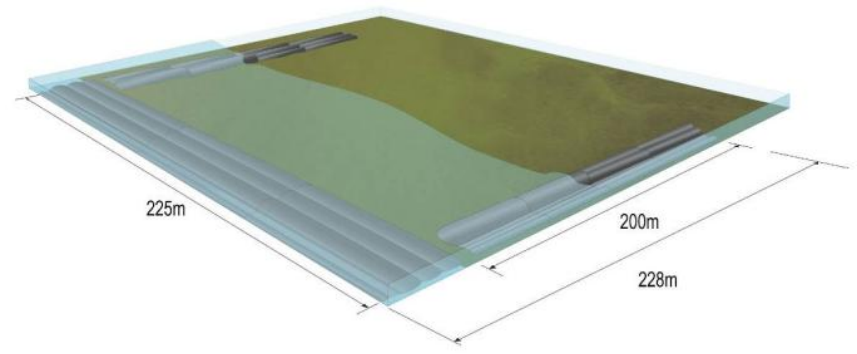

Fig. 10. The overview after construction

\section{CONSTRUCTION}

Besides the exposing part of groins on the beach, this project also required underwater operation. Geotextile tube was transported to the construction position. Before laying and anchoring the geotextile tube in place, diving staff performed preliminary work to ensure the laying position was free of disturbance and substances that might cause damage to the tube. Then the geotextile tube was laid and anchored properly. The outlet pipe from dredger was connected to the filling port of the geotextile tube, and the filling process started. There are two things needed to be overlooked during the filling process: the filling pressure and the height of the filled tube. They could affect the pressure inside the geotextile tube. Every geotextile tube has a certain capacity in withstanding inside pressure. Once the inside pressure is greater than that, it will cause damage to the tube itself. Accordingly, monitoring the output power of the dredger and the height of the geotextile tube are the most important tasks during the filling process.

A dredger and a boat for transportation were the main equipment needed for this project. The selection of dredger was very critical; it was determined by the specification of the geotextile tube and data analysis of software. The selection of dredger was done to prevent damage to the tube caused by high output power, and to avoid the extension of construction time caused by low output power. This project used a dredger with an output power of $350 \mathrm{HP}$ and an outlet pipe of 8 inches diameter, to perform the filling process with in-situ sand. The dredger is shown in Fig. 11.

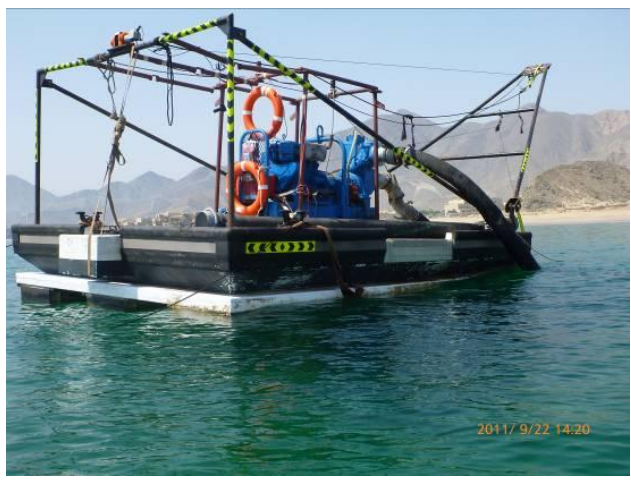

Fig. 11. The work dredger.

This project started with the construction of the two groins, then the construction of the submerged breakwater, and finally the backfilling of sand to the proposed protected area.
The construction direction was from the shoreline moving toward the sea; groins at the shore were done first, and the construction then moving outward. The estimated construction time was set for 12 months. However, the local sea state was very unstable, which eventually caused extension of the construction period. This was to be completed by August, 2012.

Neither heavy duty crane nor truck was used in this project. As mentioned, only a dredger and a boat were needed for works in the sea. Therefore, the construction did not affect the surrounding tourism. The construction method was easy and required less labor; only few divers and a dredger operator were needed to carry out the filling task. During the construction process, the geotextile tube was found covering with algae and related ecosystem (See Figs. 12 to 14). As a result, we are able to tell that the geotextile tube used is environmentally friendly, and is able to create an artificial fish reef effect around the shore.

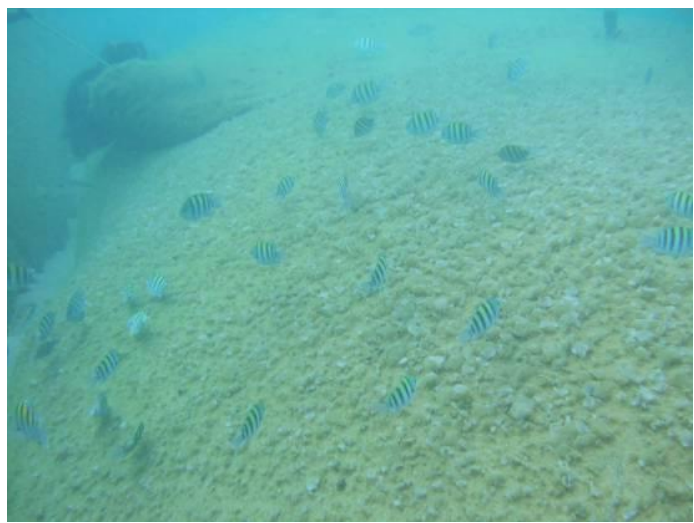

Fig. 12. The figure shows that algae attached to the geotextile tube under water.

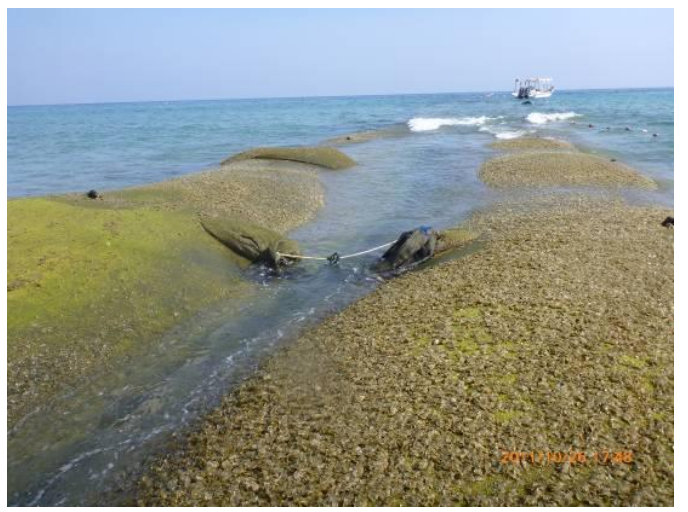

Fig. 13. The figure shows that algae attached to the geotextile tube on land

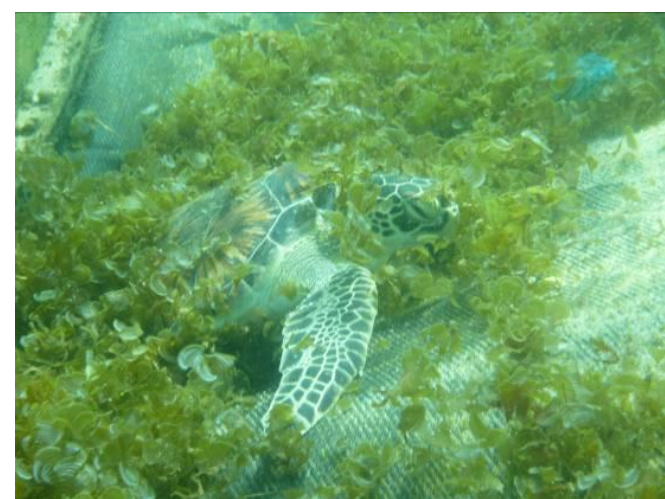

Fig. 14. The figure shows the herbivorous creatures interacting with geotextile tube. 


\section{CONCLUSION}

Geotextile tube is easy in installation and no heavy duty equipment is needed. Moreover, it has less impact to the natural environment and landscape. Comparing with conventional rubble groin construction method, geotextile tube is easier and cost-efficient; rubbles are expensive in local market, so it has an advantage in cost.

Geotextile tube has a good bonding to the natural environment. Algae are able to grow on the surface rapidly and create an ecosystem eventually. Comparing to rubble structure, geotextile tube structure is a more natural-like structure that is able to merge to the natural landscape; it functions like a groin and submerged breakwater without a clear man-made impression. This proves that the application of geotextile tube is one of the innovative methods that can replace the conventional method.

\section{REFERENCES}

[1] Coastal Engineering Manual, U.S. Army Corps of Engineers, Coastal Engineering Research Center, Vicksburg, Miss. USA, 2004.

[2] K. W. Pilarczyk, Geosynthetics and Geosystems in Hydraulic and Coastal Engineering, Rotterdam, The Netherlands: Taylor \& Francis, 2000 .

[3] E. Alvarez and B. Espinosa, "The role of the Geotextile Tubes in coastal protection and beach restoration. The experience in Yucatan, Mexico," in Proc. First Pan American Geosynthetics Conference, Cancun, Mexico, 2008.

[4] Geotextile Tube Structures Guidelines for Contract Specifications, U.S. Army Corps of Engineers, Coastal Engineering Research Center, Vicksburg, Miss. US, 2004.

[5] GeoCoPS(2.0): Supplemental Notes, ADAMA Engineering, Inc., Delaware, USA

[6] J. W. V. der Meer and K. W. Pilarczyk, "Stability of low-crested and reef breakwaters," Coastal Engineering '90, American Society of Civil Engineers, USA, pp. 1375- 1388, 1990.

[7] J. W. V. der Meer and I. F. R. Daemen, "Stability and wave transmission at low-crested rubbld-mound structures," Journal of Waterway, Port, Coastal and Ocean Engineering, ASCE, vol. 1, pp. $1-19$.

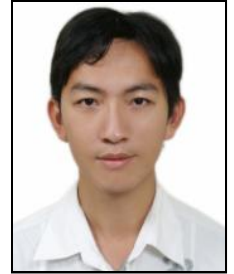

Andy Chien was born in Taichung, Taiwan on April 18,1985 . Chien received a bachelor's degree in habor and river engineering from the National Taiwan Ocean University in Keelung, Taiwan in year 2007.

Such education background automatically determined his military obligation service in the Navy as a marine engineer. While serving in the Navy, he visited different seas and ports with naval ships, and learnt the different sea conditions and port designs. Later, he joined ACE Geosynthetics in Taichung, Taiwan in 2009; he is currently holding the position of marine engineer. He has devoted himself to the expertise field of geosynthetic application in marine and hydraulic engineering, focusing on studies of geotextile tubes application, grout-filled mattress, and geotextile property in marine environment.

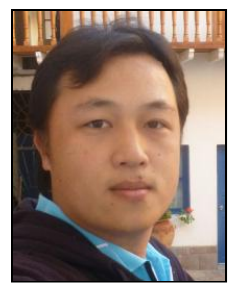

Felix Tseng was born in Taichung, Taiwan. Tseng received a master's degree in habor and river engineering from the National Sun Yat-sen University in Kaohsiung, Taiwan in year 2005.

He engaged marine engineering research from the university until present, he involved in a number of cases of pre-construction design, and had six years of construction experience to work in geotextile tube. Tseng joined ACE Geosynthetics in 2007; he is currently holding the position of marine chief engineer. He has devoted himself to the expertise field of geosynthetic application in marine and hydraulic engineering, focusing on geotextile tube, geotextile container which applied in marine environment.

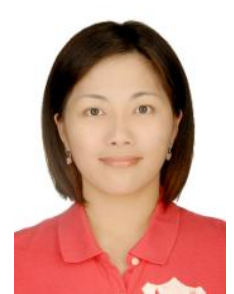

Shelly Wu was born in Taipei, Taiwan. She earned her master's degree in civil engineering from National Chiao Tung University, Hsinchu City, Taiwan in 2007. She assisted several geosynthetics research projects during her study. With the passion for geosynthetics, she joined ACE Geosynthetics in 2008. She travels different countries and shares her knowledge of geosynthetics in civil and marine engineering during her working period. Currently she holds the position of technical staff engineer and devotes herself to the expertise field of geosynthetics application in various engineering.

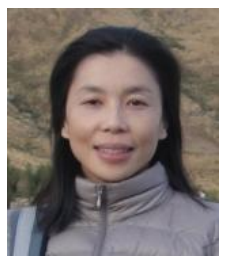

Amy Tang has enthusiastically devoted herself to the geosynthetic materials industry for more than a decade and is specialized in the civil engineering. Amy worked for the contractor and consultant company as the supervisor and the designer for years, is a practiced civil engineer in the scope of the structure design and installation of reinforced retaining walls and analysis of failures.

She currently is the technical manager of ACE Geosynthetics. 